\title{
Ginástica para Todos: notas sobre a composição coreográfica por praticantes idosas
}

Gymnastics for All: notes about choreographic composition process by elderly women

Gimnasia para Todos: notas sobre la composición coreográfica por practicantes mujeres mayores

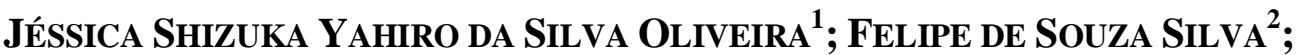 \\ FERNANDA RAFFi MENEGALdo ${ }^{3}$; MARCO ANTONIO COELHO BORTOLETO ${ }^{4}$ \\ UNIVERSIDADE ESTADUAL DE CAMPINAS, UNICAMP, CAMPINAS-SP, BRASIL
}

\begin{abstract}
RESUMO
Este estudo analisou o processo de composição e apresentação coreográfica vivido por integrantes do projeto de Ginástica para Todos (GPT) do Programa UniversIDADE da Unicamp. Caracterizada como um estudo de caso, esta pesquisa registrou depoimentos escritos de 12 participantes, que foram analisados via Análise de Conteúdo. Os registros enfatizam o processo de composição como uma oportunidade para trocas de saberes e experiências, que é intensificado pela participação ativa e pela construção coletiva, além do consequente adensamento das relações sociais - aspectos presentes na proposta pedagógica que subsidia este projeto. Ademais, a experiência de apresentar a coreografia para um grande público foi percebida como positiva e, por vezes, desafiadora, proporcionando o sentimento de superação e a socialização do processo vivido, o que reforça o potencial da GPT para esse público e o alinhamento entre as potencialidades da prática e as demandas do processo de envelhecimento.
\end{abstract}

Palavras-chave: Ginástica para Todos. Idoso. Coreografias. Educação Física.

\begin{abstract}
This study analysed the choreographic composition and performance experienced by Gymnastics for All (GfA) practioners from the UniversIDADE Program (Unicamp). Characterized as a case study, this research recorded written reports from 12 participants, which were analyzed by Content Analysis technique. The data emphasize the composition process as an opportunity for knowledge and experience exchanges, which is intensified by active participation in a collective process, besides to the consequent increase of social relations - key aspects of the pedagogical proposal used in this group. Furthermore, presenting the choreography to a large audience was perceived as positive and also challenging experience, providing the feeling of overcoming and socializing the process, which reinforces the potential of this gymnastics for elderly and the alignment between the GfA potentialities and the demands of the aging process.
\end{abstract}

Keywords: Gymnastics for All. Elderly. Choreographics Performances. Physical Education.

\section{RESUMEN}

Este estudio analizó el proceso de composición y presentación coreográfica experimentado por las integrantes del proyecto de Gimnasia para Todos (GPT) del Programa UniversIDADE de la Unicamp. Caracterizada como un estudio de caso, esta investigación registró relatos escritos de 12 participantes, que fueron analizados por medio de la Análisis de Contenido. Los registros enfatizan el proceso de composición como una oportunidad de intercambio de conocimientos y experiencias, que se intensifica con la participación activa y la construcción colectiva, además de la consiguiente densificación de las relaciones sociales, aspectos presentes en la propuesta pedagógica que subsidia este proyecto. También, la experiencia de presentar la coreografía a un público numeroso fue percibida como positiva $\mathrm{y}$, a veces, desafiante, ofreciendo la sensación de superación y socialización del proceso vivido, lo que refuerza el potencial de la GPT para este público y la convergencia entre el potencial de la práctica y las características del proceso de envejecimiento.

Palabras clave: Gimnasia para Todos. Gente Mayor. Coreografías. Educación Física.

\footnotetext{
${ }^{1}$ Graduada em Educação Física pela Unicamp. E-mail: shi_sakura@ hotmail.com. ORCID: http://orcid.org/00000003-2774-140X.

${ }^{2}$ Mestre em Educação Física pela Unicamp. E-mail: felipe msc@outlook.com. ORCID: http://orcid.org/00000002-6213-1204.

3 Mestra em Educação Física pela Unicamp. E-mail: fernandamenegaldo@hotmail.com. ORCID: http://orcid.org/0000-0002-9542-1128.

${ }^{4}$ Professor Associado do Departamento de Educação Física e Humanidades da Faculdade de Educação Física da Unicamp. E-mail: bortoleto@fef.unicamp.br. ORCID: http://orcid.org/0000-0003-4455-6732.
} 


\section{INTRODUÇÃO}

A Ginástica para Todos (GPT) é uma prática gímnica em grupo, essencialmente não-competitiva, que visa a participação inclusiva, sem distinções de idade, gênero e níveis de habilidade. Essa atividade se revela como uma prática corporal "flexível" com relação aos participantes, aos implementos utilizados, ao tipo de espaço, ao uso da música, entre outros aspectos, sendo tudo modulado conforme as características e decisões de cada grupo (MENEGALDO; BORTOLETO, 2020a), fato que, por vezes, contribui para o fomento das relações sociais entre os praticantes. Ademais, a adaptabilidade da GPT tem permitido seu desenvolvimento em diferentes contextos (escolas, universidades, academia, clubes, ONGs), ampliando a quantidade de participantes e alcançando públicos heterogêneos. Desse modo, coincidimos com as indicações da Federação Internacional de Ginástica (FIG), atualmente já endossadas por diversos estudos científicos, no sentido de tratar essa prática como um caminho para a promoção do bem-estar físico, psíquico e social, contribuindo ainda para distintos aspectos da formação humana, como o autoconhecimento, a interação social e o respeito à diversidade e às individualidades.

Para além disso, um dos melhores espaços de difusão da GPT tem sido os festivais ginásticos (PATRÍCIO; BORTOLETO; CARBINATTO, 2016), logo, eventos como a World Gymnaestrada - o maior festival não-competitivo promovido pela FIG são um exemplo da participação de pessoas das mais variadas idades, com destaque, inclusive, para a expressiva adesão de adultos e idosos (BORTOLETO et al., 2019). Nesse sentido - e corroborando com a heterogeneidade prevista para a prática da GPT , destacamos sua potencialidade para o público idoso (SIMÕES; CARBINATTO, 2016; MORENO; TSUKAMOTO, 2018; SILVA, 2020). Com efeito, parece-nos que desenvolver a prática da GPT com esse público pode representar uma oportunidade de fomentar a criatividade, a ludicidade, o compartilhamento de experiências culturais, de saberes corporais variados, bem como a possibilidade de congregar participantes com diferentes níveis de habilidade corporal, incluindo aqueles sem experiência prática prévia no campo da ginástica.

\section{GINÁSTICA PARA CORPOS EXPERIENTES: OPORTUNIZANDO A PRÁTICA DA GPT}

O Programa UniversIDADE (PU) foi criado pela Universidade Estadual de Campinas (Unicamp) em 2014 com o intuito de proporcionar atividades interdisciplinares voltadas ao público idoso de sua comunidade interna e externa. Com isso, centenas de pessoas com mais de 50 anos passaram a frequentar o programa que inclui, entre outras possibilidades, atividades esportivas (RIEDO; GARCIA; SILVA, 2017). Gratuito, o PU almeja estabelecer um vínculo entre a educação acadêmica e a educação popular, buscando a disseminação do conhecimento e do desenvolvimento humano (RIEDO; GARCIA; SILVA, 2017) para a melhor preparação dos idosos para esse importante estágio de suas vidas.

Nesse sentido, o projeto "Ginástica para Corpos Experientes” teve início em 2016 com uma ação pontual: uma oficina de GPT. Dois anos mais tarde, em 2018, uma nova proposta se materializou ainda no primeiro semestre, dessa vez com uma ação processual, composta por 15 encontros semanais realizados ao longo de quatro meses de atividades, visando oferecer uma experiência mais ampla da GPT. O êxito desse novo formato motivou a continuidade do projeto no semestre seguinte, atraindo ainda novos participantes para o espaço de prática da ginástica.

O projeto em questão se desenvolve no eixo Esporte e Lazer do PU, objetivando proporcionar uma vivência da GPT subsidiada pela proposta pedagógica do Grupo 
Ginástico Unicamp (GGU). Esta proposta apresenta, entre outros aspectos relacionados à prática, uma metodologia que promove um ambiente de compartilhamento de ideias e experiências dos praticantes, além de participação e voz ativa, respeito às individualidades e aumento da interação social (GRANER; PAOLIELLO; BORTOLETO, 2017). Além disso, tem como um de seus pilares a composição coreográfica (CARBINATTO; FURTADO, 2019) que, a partir da referida proposta pedagógica, constitui-se como um processo de composição coletiva de coreografias, a partir do qual pode-se experienciar de forma intensa esse espaço dialógico de prática da ginástica.

Assim, este estudo teve como objetivo analisar o processo de composição coreográfica vivenciado pelas integrantes do projeto Ginástica para Corpos Experientes, identificando as experiências e percepções mais significativas durante o processo a partir da perspectiva das praticantes ${ }^{5}$. Destaca-se, ainda, que o processo de composição coreográfica é reconhecido na literatura científica da GPT como fundamental para o desenvolvimento da prática, possibilitando o fomento a vários potenciais particulares da GPT (MENEGALDO; BORTOLETO, 2020a). Ademais, ao abordar a prática da GPT em grupos de idosos no Brasil, Silva (2020) confirmou a baixa visibilidade e o escasso tratamento dessa temática pela literatura especializada. Nesse sentido, todos esses aspectos, combinados ao reconhecimento da GPT como uma alternativa promissora para a promoção da saúde e da qualidade de vida, justificam a realização deste estudo, que poderá contribuir para o debate e o fomento dessa prática gímnica para os idosos.

\section{MÉTODO}

\section{CARACTERIZAÇÃo da PESQUiSa}

O presente estudo caracteriza-se como uma pesquisa exploratória e descritiva, de natureza qualitativa (MINAYO, 2010), configurando-se como um estudo de caso, em concordância com Triviños (1987).

\section{PARTICIPANTES, CONTEXTo E ASPECTOS Éticos}

Participaram desta pesquisa 12 pessoas idosas, sendo 11 mulheres e um homem, regularmente matriculadas no projeto "Ginástica para Corpos Experientes" do Programa UniversIDADE durante o segundo semestre de 2018. Ademais, em concordância com o objetivo do Programa UniversIDADE, a média de idade das integrantes é de 59 anos (mínimo 52 e máximo 81). Os encontros aconteceram semanalmente, às terças-feiras, e foram realizados no Laboratório Integrado de Ensino, Pesquisa e Extensão (LABFEF) e no Espaço de Dança da Faculdade de Educação Física (FEF) da Unicamp.

O cronograma de atividades do semestre em questão contou com 15 encontros, todos mediados por dois professores: uma graduanda e um mestrando, ambos vinculados à FEF-Unicamp. Além dos professores, os encontros também contaram com a participação de professoras(es) especialistas em GPT e em áreas afins, proporcionando uma troca entre esses profissionais. Consequentemente, houve a oferta de diferentes manifestações da cultura corporal que flertam com essa prática gímnica, contribuindo para a ampliação do repertório gestual das praticantes, bem como para o fomento da exploração criativa de implementos (materiais), do espaço, da música e da expressão que são elementos fundamentais para o processo de composição coreográfica.

\footnotetext{
${ }^{5}$ Para falar especificamente do grupo cujos relatos analisamos, faremos a concordância textual no feminino por se tratar de maioria de participantes que se identificam como mulheres.
} 
A participação na pesquisa foi consentida, individualmente, por meio do preenchimento do Termo de Consentimento Livre e Esclarecido (TCLE), que apresentava as premissas éticas deste estudo, seus objetivos e os procedimentos metodológicos. Na mesma ocasião, as participantes também consentiram com o registro de imagens (fotografias) produzidas nos encontros semanais. Ainda, os nomes das participantes foram substituídos pela sigla CE (Corpo Experiente) e numerados aleatoriamente. Todos os cuidados éticos detalhados acima foram previstos no projeto aprovado pelo Comitê de Ética em Pesquisa da Unicamp (via Plataforma Brasil), sob parecer $n^{\circ} 3.196 .127$.

\section{INSTRUMENTOS E PROCESSO DE INVESTIGAÇÃO}

Como técnica para a coleta de dados, utilizamos registros escritos, que foram realizados individualmente e agrupados no "Diário de Experiências" (DE). O DE consistia em um caderno que era levado para casa pelas praticantes, após o término de cada aula, para que elas elaborassem seus registros. Essa atividade foi iniciada depois do terceiro encontro, sendo o DE levado por uma integrante que deveria devolvê-lo no encontro seguinte com seu respectivo depoimento. Feita a devolução, os professores destacavam a(s) folha(s) que continha(m) o depoimento e, posteriormente, repassavam os DE para outra integrante. A opção por retirar os depoimentos do DE antes de encaminhá-lo para outra integrante é justificada tanto pela preservação do anonimato da participação na pesquisa como também para que os depoimentos anteriores não influenciassem os registros seguintes.

Dessa forma, ao término do projeto foram obtidos 12 depoimentos, uma vez que todas aceitaram registrar suas experiências e percepções no DE. A ordem das integrantes para a realização do registro não foi previamente estipulada; a cada encontro, voluntariamente, uma das participantes que ainda não havia realizado o registro, se disponibilizava a fazê-lo na semana corrente. Em formato livre, seu objetivo era apresentar uma descrição das percepções acerca das dinâmicas realizadas em aula, incluindo, portanto, a composição coreográfica. Ademais, a intenção em deixá-las livres para a elaboração do depoimento foi proposital, para que os registros escritos revelassem as percepções e as experiências mais significativas na perspectiva das integrantes.

Além do $\mathrm{DE}$, as integrantes também foram convidadas a elaborarem outro registro, intitulado "Balanço das Experiências" (BE). Coletado on-line, sua elaboração também foi individual e se deu após a última apresentação do grupo, que coincidiu também com o término das atividades do referido projeto. Dessa forma, todas as integrantes enviaram, por e-mail, um relato sobre a participação no projeto "Ginástica para Corpos Experientes", com ênfase na participação em dois eventos, quando apresentaram a composição coreográfica elaborada pelo grupo no referido semestre. Esses eventos foram o XXIV Festival da Faculdade de Educação Física da Unicamp e o Encerramento das atividades do PU 2018, tendo ambos ocorrido em dezembro de 2018.

Assim, ao final do semestre foi possível reunir 24 registros (depoimentos), sendo 12 deles sobre o processo - ou seja, as dinâmicas de exploração, a construção coletiva e a composição coreográfica, registrados no DE - e outros 12 sobre o produto, isto é, sobre a coreografia e a experiência de se apresentar em público, relatados no BE.

\section{ANÁLISE DE DADOS}

Para subsidiar e sistematizar a análise dos depoimentos, adotamos a proposta de Análise de Conteúdo sugerida por Krippendorff (2014). Para isso, os registros foram cuidadosamente lidos, iniciando, assim, a fase de análise. Primeiramente, houve a 
intenção de identificar as unidades de registro e as unidades de contexto. Em seguida, tivemos (I) a separação por categorias; (II) as conclusões com base nos resultados obtidos; (III) o reagrupamento das categorias; (IV) a produção de narrativas temáticas; e, por fim, (V) a interpretação dos resultados obtidos e o diálogo entre as narrativas e a literatura específica da área.

Esse processo foi realizado com os dados obtidos por ambos os instrumentos: DE e BE. Nos dados oriundos do DE, foram identificadas (etapas I, II e III) e discutidas (etapas IV e V) cinco categorias: 1) processo de construção coletiva, 2) participação ativa, 3) habilidades sociais e amizades, 4) acessibilidade e respeito dos limites individuais e 5) tematização. Já os dados obtidos pelo BE, geraram três categorias de análise: 1) superação e melhora da autoestima, 2) sensação de produtividade-utilidade e 3) relação com os espectadores.

\section{RESULTADOS E DISCUSSÃO}

O processo analítico dos dados resultou em uma série de categorias que serão aqui apresentadas em dois momentos. Primeiramente, traremos as categorias oriundas do DE que fazem referência, portanto, ao "Processo de composição coreográfica". Posteriormente, abordaremos as categorias resultantes das análises realizadas com os registros do BE, que tratam, especificamente, sobre "A experiência de apresentar nos eventos".

\section{SOBRE O PROCESSO DE COREOGRAFAR}

Antes de apresentar os relatos e as experiências na perspectiva das integrantes, consideramos importante descrevermos, ainda que de forma sucinta, como foi estruturado o processo de composição coreográfica. Presente desde as primeiras aulas, as dinâmicas de construção coletiva de sequências de movimentos - muitas vezes realizadas no momento final da aula, com base nos saberes gímnicos abordados naquele encontro - foram, gradualmente, permitindo que o grupo compreendesse a ideia da participação ativa nesses momentos de composição, tornando essas dinâmicas parte das atividades do grupo, assim como estimulando a criatividade e a habilidade da cooperação (MENEGALDO, 2018).

Dessa forma, tendo em vista a participação nos eventos no fim do semestre e estando as integrantes do grupo minimamente familiarizadas com a proposta utilizada para o desenvolvimento das aulas, foi iniciado no nono encontro o processo de composição da coreografia para apresentação. Destarte, decidiu-se utilizar os arcos (aparelhos oficiais da Ginástica Rítmica) como implemento. Eles foram apresentados para as integrantes como uma possibilidade de material para a GPT (ANTUALPA; MENEGALDO, 2016) durante a oficina de "Manipulação de materiais", ministrada por uma convidada externa na sétima aula. A escolha desse aparelho para a coreografia final parece ter sido reflexo da experiência positiva das participantes durante a oficina, na qual elas puderam explorar diversas formas de manipulá-lo, tanto individualmente como também em grupo, ao construírem movimentos de cooperação direta por meio dele.

Com o material decidido, os debates se voltaram para a escolha de outros elementos fundamentais da coreografia: tema e música. O grupo decidiu, após alguns debates mediados pelos professores, uma temática que remetesse à ideia das fases da vida - infância, juventude e vida adulta -, sistematizando uma "linha do tempo". Com base nisso, uma das integrantes deu a sugestão de nomear a coreografia como "Trem da 
vida", ideia que foi acatada pelas demais e que conduziu o processo de escolha da música a ser utilizada.

Tomadas as decisões, o grupo, então, dedicou-se à elaboração da coreografia per se, isto é, à união do material, do tema e da música aos elementos corporais em uma sequência de movimentos. Sobre esse processo, a primeira e mais frequente categoria identificada no discurso das integrantes foi justamente acerca do método utilizado para tal construção, que é fundamentado, como dito anteriormente, na proposta pedagógica do GGU (GRANER; PAOLIELLO; BORTOLETO, 2017; PAOLIELLO et al., 2014). As passagens indicam, a princípio, que o processo de construção coletiva (ALMEIDA, 2016) foi percebido como uma estratégia que não apenas congrega os movimentos aprendidos, mas que, por meio da interação entre as praticantes, possibilita um exercício de pensar sobre o movimento e sobre as possibilidades de criação e diálogo com outros elementos (espaço, tempo, música, tema) (SOARES; ALMEIDA; BORTOLETO, 2016). Dessa forma, ele "[...] oportuniza criatividade, trabalho em grupo e relacionamento interpessoal" (CE2).

Ainda sobre essa metodologia, CE3 comenta que ela "[...] coloca os alunos para pensar, se movimentar, argumentar, questionar, dar opiniões, interagir uns com os outros $[. .$.$] é uma atividade muito interessante". Por sua vez, CE10 relata que:$

\begin{abstract}
[...] em grupos, conversamos sobre brincadeiras da infância, cada um foi falando, fazendo uma viagem ao passado [...] uma turma apresentou para a outra as brincadeiras em uma sequência, foi muito bom. Nosso grupo montou uma coreografia integrando as brincadeiras com os movimentos. Foi uma atividade que englobou várias partes do corpo com movimentos, dança, memorização, coordenação.
\end{abstract}

Dentro dessa proposta, uma dinâmica intitulada "soma de frases" (PAOLIELLO et al., 2014) figura como um dos caminhos possíveis para a construção coletiva. Individualmente, os praticantes criam pequenas sequências de movimentos que, em seguida, são compartilhadas em duplas, podendo se combinar e formando uma única sequência. Essa pequena composição é posteriormente compartilhada em quartetos, formados por duas duplas da fase anterior, e o objetivo é aumentar a sequência de movimentos, acrescentando novas ideias. A mesma dinâmica de agrupamento das sequências pode ser realizada mais vezes, dependendo do tamanho do grupo.

No projeto, devido ao número de participantes, a soma de frases era realizada até que, em quartetos, as praticantes pudessem construir uma minicoreografia. Na visão da CE7, essa estratégia é "[...] uma ótima forma de promover o movimento livre, de forma divertida e criativa". O dinamismo dessas ações, que são mediadas pelos professores, promove uma participação mais ativa, que parece exigir mais das integrantes: "[...] uau! Ideias, discordâncias, aceitação, paciência, tolerância, empolgação... foi um exercício de controle das emoções que explodia na gente!” (CE4).

Essa participação ativa, que também figura como elemento da proposta utilizada, parece ter sido identificada como um componente importante do dia a dia das aulas e, além disso, como algo que não é comum em outros espaços de práticas corporais. As metodologias utilizadas estão associadas, geralmente, a abordagens e propostas mais verticalizadas, assim, "[...] pelo fato de as aulas virem apenas com ideias 'précolocadas' pelos professores, o grupo participa integralmente das montagens das coreografias, exercendo o cérebro, corpo e união do grupo" (CE3). Essa categoria é recorrente nos registros do DE e está, em todas as passagens, relacionada a habilidades sociais e a amizades (SENNETT, 2012): “[...] tudo vai sendo cuidadosamente 
construído no decorrer do semestre. E vamos aprendendo a juntar ideias, compartilhar, unir, discordar com empatia, respeitar e criar" (CE4).

Ademais, a relação entre participação ativa e desenvolvimento de habilidades sociais merece destaque, pois converge com muitos relatos de experiência e pesquisas da área, que dizem que a GPT promove a interação social, ou ainda, a socialização (MENEGALDO; BORTOLETO, 2020b; SILVA, 2020). De forma mais profunda, essa relação pode ser explicada na medida em que entendemos a cooperação - elemento chave da prática da GPT a partir de seu entendimento como uma prática em grupo, ou ainda, sociomotriz (PARLEBAS, 2001; MENEGALDO; BORTOLETO, 2020a) - como uma habilidade social, nos termos de Sennett (2012). Dessa forma, as participantes, ao serem expostas semanalmente a dinâmicas essencialmente colaborativas que promovem o exercício de expor opiniões, concordar, discordar, dialogar, preferencialmente em uma perspectiva dialógica, acabam aprimorando essa habilidade: "[...] torcemos o nariz para algumas sugestões, adoramos outras, tivemos mais empatia com alguns do grupo, mas no final foi um trabalho, literalmente, em conjunto!"' (CE4).

Assim, a prática da GPT responde a demandas físicas, mas também sociais do processo de envelhecimento (BUKOV; MAAS; LAMPERT, 2002; HUXHOLD; MICHE; SCHÜZ, 2014; PINTO; NERI, 2017), momento da vida comum a todas as integrantes do projeto. O convívio nesse espaço, portanto, extrapola as expectativas comumente associadas à prática da atividade física por esse público e tem como produto não apenas o movimentar-se. O que nos chama a atenção após esse processo é que, mais do que uma coreografia de ginástica, amizades são construídas no espaço de prática (MENEGALDO; BORTOLETO, 2020c). CE9 corrobora essa ideia, dizendo que a prática, "[...] além de mexer com nosso corpo, estimula a criatividade, possibilita a socialização, pois a cada aula entrelaçamos nossas amizades".

Nesse sentido, identificamos nos registros da CE6 uma fala muito potente: "[...] a princípio, eu não estava disposta a aceitar fazer parte da apresentação. Porém, como havia criado uma conexão com o grupo, fui forçada, ou melhor, impulsionada por essa amizade". Então, após ter relatado ter muita vergonha e timidez, CE6 indica o papel das relações de amizade construídas no grupo para uma superação pessoal: participar de uma coreografia e se apresentar em público. Além disso, nas entrelinhas do DE, foi possível identificar que a superação é algo latente também para outras integrantes, caminhando lado a lado com a categoria de análise: acessibilidade e respeito dos limites individuais. Entre as passagens que destacam essa virtude da prática, temos o comentário que CE3 fez durante as aulas: "[...] os limites são sempre respeitados, integrando todos ao mesmo tempo, sem discriminações". Além disso, CE7 afirma que "[...] todos participam de acordo com suas possibilidades e condições físicas, interagindo com o grupo de alguma forma".

Por sua vez, essa acessibilidade está relacionada à ausência de regras e códigos gestuais, possibilitando um outro lugar para a prática da GPT que não o da performance: o lazer. Estudos anteriores já trataram dessas experiências e teceram reflexões sobre a prática da GPT como uma vertente da ginástica voltada ao lazer (FERNANDES; EHRENBERG, 2012; FIORIN-FUGLSANG; PAOLIELLO, 2008; OLIVEIRA, 2007), perspectiva que corrobora as premissas da FIG acerca dessa prática gímnica (FIG, 2019). Considerando isso, a GPT oportuniza uma prática que contempla, já na teoria, corpos com muita ou nenhuma experiência corporal e gestos embebidos de muito ou nenhum conhecimento gímnico, em uma liberdade que tem relação com a flexibilização do conceito de "técnica", nos termos de Bortoleto (2008).

Para além da teoria, propiciar um espaço de prática da GPT que seja coerente com esse potencial depende também da metodologia empregada para seu desenvolvimento. 
Sobre isso, a CE8 comenta que durante as aulas experienciadas no projeto, as miniapresentações em grupo derivadas das dinâmicas de construção coletiva (após as dinâmicas de soma de frases citadas anteriormente, por exemplo) são momentos confortáveis de "exposição", pois promovem o "respeitar dos limites individuais". Dessa forma, fica evidente que o professor ou mediador também tem um papel importante na materialização desse potencial inclusivo, ao propor um desenvolvimento da prática que dialogue com a diversidade.

Também associada ao método, destacamos a última categoria de análise, intitulada tematização. Composta por passagens que enalteceram o trabalho da composição coreográfica, a tematização (ALMEIDA, 2016) aparece como um facilitador nas dinâmicas coletivas, fomentando um espaço criativo de prática da ginástica. A integrante CE8, após a aula em que o tema da coreografia final foi decidido, registrou o seguinte depoimento:

[...] nossa apresentação será supermovimentada: começaremos como idosas, faremos atividades resgatando nossa cronologia... teremos a fase adulta onde trabalhamos e a vida corre... na infância nós brincamos e terminaremos resgatando nossa criança interior, mostrando que não somos "só" idosas!

Após esse dia, o grupo se empenhou em trazer elementos que tivessem relação com o tema e que pudessem ser incorporados - em forma de movimentos - à coreografia. As brincadeiras da infância foram um dos elementos explorados pelas integrantes. A praticante CE10 indica que essa tematização proporciona um envolvimento maior com a composição e que isso facilita o engajamento do grupo com o tema e os momentos criativos do processo de composição. Em outra passagem é possível identificar esse aspecto tratado com muita leveza pela integrante CE6, que definiu a construção coletiva como "[...] uma série de brincadeiras de criança que culminou na preparação para a apresentação da coreografia".

Acerca disso, alguns pontos merecem destaque. Em primeiro lugar, ressaltamos a tematização como uma estratégia que, da mesma forma que a utilização de implementos (materiais), auxilia no processo de composição coreográfica coletiva, figurando como um disparador, um ponto de partida ou ainda uma "ideia-guia" para as explorações e dinâmicas anteriores. Isso permite que participantes em geral tenham liberdade criativa, ainda que a coreografia seja desenhada pela temática escolhida (ALMEIDA, 2016). Além disso, é importante pensarmos que elementos como os implementos (material) ou a temática podem também contribuir para a formação de grupos com baixo repertório gímnico, isto é, com integrantes que ainda não possuem domínio de muitas técnicas corporais (movimentos ginásticos) para compor as coreografias. Nesse sentido, o uso bem explorado de um material alternativo (IWAMOTO et al., 2016) ou ainda a utilização do tema em momentos expressivos ou "cênicos" durante a coreografia podem ser estratégias interessantes para aumentar as possibilidades estéticas no momento da composição.

\section{A EXPERIÊNCIA DE APRESENTAR NOS FESTIVAIS}

A participação em eventos e festivais ginásticos tem um papel importante para praticantes de GPT, como ressaltam Patrício e Bortoleto (2015), permitindo a interação com pessoas de diferentes faixas etárias, oportunizando uma maior diversidade gímnico-cultural e ofertando diferentes experiências estéticas. Pensando também o contexto deste estudo, esses benefícios parecem se multiplicar, pois, para além dos aspectos elencados, a participação nos eventos e a consequente apresentação da coreografia tiveram outros desdobramentos na perspectiva das integrantes. 
Entretanto, antes de adentrar nesses relatos, detalhamos, de forma breve, os dois eventos nos quais o grupo teve a oportunidade de participar: a) Festival da FEFUnicamp, realizado semestralmente pela instituição, que congrega apresentações de ginástica, circo, dança e outras práticas, com participantes de diferentes faixas etárias e contextos (extensão universitária, alunos da instituição, escolas, clubes, associações); b) Evento comemorativo de encerramento das atividades do PU, que reúne participantes de todas as suas linhas (Arte e Cultura; Esporte e Lazer; Saúde Física e Mental; Sociocultural; e Geração de Renda). Ambos os eventos ocorreram após a decima quinta aula do projeto, ou seja, após um período que nos parece fundamental para a consolidação do grupo, para o entendimento da proposta e da relevância que a apresentação pública tem como "amalgama" do processo.

Dessa forma, a participação nos eventos desdobrou-se, aos olhos das integrantes, em uma experiência única de superação e melhora da autoestima. Apresentar-se no festival foi, para todas, uma experiência positiva e, para mais da metade delas, uma vivência diferente, dado que não haviam participado de apresentações em público anteriormente. Nesse sentido, CE1 traz um registro sobre como se sentiu no momento da apresentação, trecho que, a nosso ver, flerta não apenas com a questão da autoestima, mas também com uma sensação de segurança, ao relatar não sentir vergonha alguma durante sua participação: “[...] meu Deus! Participar do festival! Que incrível! Eu me senti estrela, poderosa, confiante, sem nenhum pingo de vergonha!". Também sobre a exposição causada pela apresentação, CE6 - que a princípio não participaria da coreografia por conta de sua timidez, como mencionado - foi convencida a participar por conta dos laços criados com as integrantes do grupo, comentando que: "[...] quando decidi participar, o curso acabou tomando outro rumo para mim. E, como consequência, acabo de me apresentar em público... duas vezes!". Novamente, é possível identificar nas entrelinhas a questão da superação, além da importância do "tornar público" a composição coreográfica, oferecendo uma experiência desafiadora para muitas das participantes. Depoimentos nesse sentido também foram registrados por Silva (2020), ao entrevistar praticantes idosas de GPT.

Essas falas também nos remetem a uma valorização de si e indicam, como em outras passagens, que o ato de se apresentar materializa uma sensação de superação ou, em outras palavras, que o "tornar público" consagra essas superações, possibilitando que elas mostrem para si e para seus pares movimentos e ações que elas nem mesmo acreditavam que conseguiriam fazer. Um trecho do registro no BE da integrante CE11 ilustra perfeitamente esse ponto: "[...] participar do festival foi um desafio para mim. Pude me conhecer melhor, me sentir forte, otimista, com a certeza de que eu consigo, eu posso... eu venci! Me senti muito orgulhosa de mim!".

A partir desses depoimentos, então, é indiscutível que para esse grupo de praticantes a apresentação da coreografia teve desdobramentos positivos. No entanto, para entender esses trechos é necessário resgatar o contexto no qual essas pessoas estão inseridas: o processo de envelhecimento. Considerando isso, é importante nos atentarmos para a construção de estereótipos durante essa etapa da vida, visto que a maioria deles são estabelecidos externamente. Ademais, o declínio de uma vida ativa no mercado de trabalho também se combina a essa questão, sendo um aspecto que pode levar à sensação de exclusão ou inutilidade (BULLA; KAEFER, 2006). Assim, a pessoa idosa pode ser conduzida a crer que suas possibilidades de ação se esgotaram ou foram minimizadas por conta das mudanças de sua vida cotidiana (BUKOV; MAAS; LAMPERT, 2002; KIM et al., 2014; LEVY et al., 2002), logo, experienciar algo diferente a essa altura da vida a faz lembrar e crer em suas potencialidades e alternativas também durante o envelhecimento. 
Essa discussão nos encaminha para a segunda categoria de análise dos dados do BE: sensação de produtividade-utilidade. Nela, pudemos identificar passagens que corroboram a literatura e que reforçam a importância de uma vida ativa, não apenas no sentido do exercício físico per se, mas de uma participação que prevê a interação social, a reflexão e o fomento à criatividade, a exposição a desafios e tarefas inovadoras e a não subestimação das capacidades físicas e intelectuais. Dessa forma, vê-se claramente um alinhamento potente entre as demandas do processo de envelhecimento (KIM; KIM; KIM, 2013) e a proposta do projeto, que permite esse envolvimento para além da atividade física e de seus benefícios fisiológicos.

Mais especificamente, a possibilidade de participação ativa durante as aulas e as dinâmicas propostas viabilizam que as integrantes tenham uma coautoria nesse espaço, que se torna, mais do que um local de prática, um local de engajamento e produção de algo. A participante CE9 faz uma comparação interessante ao falar sobre a coreografia, dizendo que "[...] quando jovem, havia feito Ginástica Rítmica..., mas quer saber? Agora eu consegui produzir muito mais do que naquela época!”. Com essa passagem ela indica essa sensação de contribuir para a construção de algo no espaço de prática. Já CE11 traz um relato similar que indica, inclusive, uma relação entre esse tópico e o engajamento do grupo: "[...] conseguir produzir e apresentar uma excelente coreografia... Acredito que isso nos fez despertar para o espírito do exercício físico em equipe!”.

Assim, a questão das relações sociais, tão evidente nos registros do DE, também aparece nas entrelinhas dos registros do BE, como é possível identificar na fala presente no parágrafo anterior. No entanto, por tratar-se de dois momentos pontuais - as duas apresentações - os registros evidenciam maior ênfase no contato com um público mais jovem, no caso do Festival da FEF, e com os pares, durante o evento de encerramento do PU. Nesse sentido, adentramos em nossa última categoria, na relação com os espectadores. Primeiramente, sobre o encerramento do PU, foi possível identificar algo próximo do que poderíamos denominar como um reconhecimento pelos pares durante o ato da apresentação, tendo em vista que os espectadores do evento eram, em sua maioria, colegas e conhecidos das integrantes do projeto, uma vez que frequentam outras atividades ofertadas pelo PU. Dessa forma, a fala da CE12 ilustra esse momento e ressalta os elogios recebidos pelos seus pares após a apresentação: “[...] meus colegas do coral e outros que me conhecem de outras oficinas vieram dar parabéns e elogiaram nossa apresentação!". Essa fala nos remete não só ao fato de um compartilhamento entre os pares, mas também à valorização daquilo que foi compartilhado, o que, nesse caso, pode ser identificado como elogio.

Combinado a isso, outras passagens interessantes e que parecem indicar satisfação e alegria dizem respeito aos espectadores e participantes do Festival da FEF, em que as integrantes comentam terem tido contato com um público jovem: "[...] foi muito bom a experiência de se apresentar em um Festival de jovens universitários!" (CE12). Essa vivência de dividir o momento com outras faixas etárias vem sendo explorada na literatura, principalmente com relação a práticas intergeracionais (CARLETO, 2013; MARTINS, 2019; MOTA; NEVES, 2019; FRANÇA et al., 2010), muitas vezes destinadas à compreensão dessas relações no ambiente familiar.

No entanto, especificamente acerca das práticas corporais, muito ainda pode ser explorado. No caso da GPT, esse ambiente de troca entre diferentes gerações é uma opção não apenas durante eventos ou festivais, mas também e principalmente na constituição de grupos. Por conta de suas particularidades, essa prática gímnica se molda facilmente aos grupos compostos por diferentes faixas etárias, podendo transformar-se em uma opção de prática que, para além dos benefícios aqui elencados, 
também pode contribuir para a disseminação das práticas intergeracionais que, em concordância com França et al. (2010), promovem a solidariedade intergeracional. Esta, por sua vez, auxilia "[...] não só na quebra de preconceitos sociais frente ao envelhecimento, como na melhoria da qualidade de vida de jovens e idosos" (FRANÇA et al., 2010, p. 521). Encerramos, portanto, a análise dessa categoria com a fala da CE1, quando comenta em seu registro: "[...] sou cada dia mais jovem porque vocês existem na minha vida!".

\section{CONSIDERAÇÕES FINAIS}

Entre as oito categorias de análise aqui apresentadas, algumas delas merecem destaque ao discutirmos a prática da GPT pelo público idoso. Com relação às discussões provenientes dos $\mathrm{DE}$, isto é, dos registros do processo composição coreográfica, destacamos a participação ativa e o desenvolvimento de habilidades sociais e amizades no interior do grupo, frutos de uma prática da GPT subsidiada por uma proposta pedagógica que fomenta a construção coletiva não apenas da coreografia, mas do espaço de prática. Ademais, merece destaque também a categoria superação e melhora da autoestima, discutida a partir dos dados coletados após as apresentações nos eventos (BE). Essas categorias se sobressaem na medida em que convergem com as demandas, previstas na literatura, acerca do processo de envelhecimento, viabilizando um espaço de prática onde as integrantes: não são apenas "alunas", mas coautoras dos processos ali desenvolvidos; não se beneficiam somente das melhoras fisiológicas da atividade física, mas constroem amizades, engajam-se e desenvolvem habilidades comunicativas e cooperativas; e, por fim, não cumprem apenas o senso comum de um programa de atividade física (exercitar-se), mas tornam público o produto desse espaço de prática e desafiam-se em novas experiências.

Destarte, embora este estudo indique benefícios e efeitos positivos desse espaço de prática da GPT para as integrantes do grupo, é necessário reconhecer que o projeto "Corpos Experientes" está ainda em construção, considerando sua trajetória iniciada em 2018. Nesse sentido, os registros também indicam alguns possíveis ajustes ou alterações de maneira a aprimorar a realização das aulas e o desenvolvimento, por exemplo, de uma composição coreográfica: destinar mais encontros para os ensaios da coreografia é uma demanda que foi sugerida pelas alunas e também percebida pelos professores do projeto. Além disso, ampliar e diversificar os espaços de apresentação, inclusive para a comunidade externa à Unicamp, parece ser uma ideia viável que não só diversificaria os contextos de apresentação, mas também permitiria alcançar mais pessoas e propagar a possibilidade da prática da GPT pelo referido público.

Considerando o exposto e reconhecendo os limites da pesquisa por se tratar de um estudo de caso, enfatizamos a importância de um olhar mais atento para o público idoso no que diz respeito ao espaço destinado a ele dentro no universo da GPT. Finalizamos, portanto, propondo uma pergunta: quais são os produtos que a GPT pode oferecer aos seus públicos? Tendo em vista as diferentes formas de expressão que a GPT pode proporcionar, não temos dúvidas de que os caminhos para o desenvolvimento dessa prática são múltiplos no que diz respeito à metodologia (processo pedagógico) e sabemos que essas escolhas podem favorecer ou não o processo de desenvolvimento individual e social tão presente nos depoimentos. O que apontamos, portanto, a partir dessa experiência assim como de vivências anteriores, é que o desenvolvimento dessa prática com base em uma proposta coletiva, que promova a participação ativa, respeitosa e empática, pode contribuir para o equilíbrio de conflitos e a obtenção de 
consensos. Com isso, o processo tende a intensificar as relações entre as participantes podendo resultar, para além de belas composições coreográficas, em amizade, superação, engajamento e reconhecimento social, contribuindo, portanto, para uma melhor experiência dessa etapa da vida.

\section{REFERÊNCIAS}

ALMEIDA, T. L. Composição coreográfica coletiva e tematização como estratégias pedagógicas para o ensino/aprendizagem da acrobacia coletiva. 2016. 157 p. Dissertação (Mestrado em Educação Física) - Faculdade de Educação Física, Universidade Estadual de Campinas, Campinas, 2016.

ANTUALPA, K. F.; MENEGALDO, F. R. Diálogo da ginástica rítmica com a ginástica para todos: contribuições para a composição coreográfica. In: OLIVEIRA, M. F.; TOLEDO, E. (org.). Ginástica para todos: possibilidades de formação e intervenção. Anápolis: Editora UEG, 2016. p. 181-200.

BORTOLETO M. A. C.; HEINEN, T.; JUN, S.; TOLEDO, E.; SCHIAVON, L.; PASQUA, L.; OLIVEIRA, M.; MENEGALDO, F. R. What motivates people to participate in a non-competitive gymnastics festival? - a case study of world gymnaestrada. Science Gymnastics Journal, v. 11, n. 1, p. $15-22,2019$.

BORTOLETO, M. A. C. Uma reflexão sobre o conceito de técnica na ginástica geral. In: PAOLIELLO, E. Ginástica geral: experiências e reflexões. São Paulo: Phorte, 2008. p. 167-190.

BUKOV, A.; MAAS, I.; LAMPERT, T. Social participation in very old age: cross-sectional and longitudinal findings from BASE: Berlin Aging Study. Journals of Gerontology Series B: Psychological Sciences and Social Sciences, v. 57, n. 6, p. 510-507, 2002.

BULLA, L. C.; KAEFER, C. O. Trabalho e aposentadoria: as repercussões sociais na vida do idoso aposentado. Textos \& Contextos, v. 2, n. 1, p. 1-8, 24 out. 2006.

CARBINATTO, M. V.; FURTADO, L. N. R. Choreographic process in Gymnastics for all. Science of Gymnastics Journal, Ljubljana, v. 11, n. 3, p. 343-354, 2019.

CARLETO, D. G. S. Relações intergeracionais de idosos mediadas pelas tecnologias de informação e comunicação. 2013. 79 p. Dissertação (Mestrado em Ciências) - Escola de Engenharia de São Carlos, Faculdade de Medicina de Ribeirão Preto, Instituto de Química de São Carlos, Universidade de São Paulo, São Carlos, 2013.

FIG. Fedération Internationale de Gymnastique. Gymnastics for all manual. Lausanne: FIG, 2019.

FERNANDES, R. C.; EHRENBERG, M. C. A Ginástica para todos na sua relação com as atividades físicas orientadas para o lazer. EFDeportes, v. 15, n. 166, 2012.

FIORIN-FUGLSANG, C. M.; PAOLIELLO, E. Possíveis relações entre a Ginástica Geral e o Lazer. In: PAOLIELLO, E. Ginástica geral: experiências e reflexões. São Paulo: Phorte, 2008. p. 97-120.

FRANÇA, L. H. F. P.; SILVA, A. M. T. B.; BARRETO, M. S. L. Programas intergeracionais: quão relevantes eles podem ser para a sociedade brasileira? Revista Brasileira de Geriatria e Gerontologia, v. 13, n. 3, p. 519-531, 2010.

GRANER, L.; PAOLIELLO, E.; BORTOLETO, M. A. C. Grupo Ginástico Unicamp: potencializando as ações humanas. In: BORTOLETO, M. A. C.; PAOLIELlO, E. (org.). Ginástica para todos: um encontro com a coletividade. Campinas: Editora da Unicamp, 2017. p. 165-198.

HUXHOLD, O.; MICHE, M.; SCHÜZ, B. Benefits of having friends in older ages: Differential effects of informal social activities on well-being in middle-aged and older adults. Journals of Gerontology Series B: Psychological Sciences and Social Sciences, v. 69, n. 3, p. 366-75, 2014. 
Jéssica S. Y. S. Oliveira; Felipe S. Silva; Fernanda R. Menegaldo; Marco Antonio C. Bortoleto

IWAMOTO, T. C.; MARINS, P.R.C.S.; ROCHA, P.H.T.; MORAES, J. S. Ginástica para todos e as possibilidades de materiais adaptados e alternativos para a prática pedagógica e construção coreográfica. In: OLIVEIRA, M. F.; TOLEDO, E. (org.). Ginástica para todos: possibilidades de formação e intervenção. Anápolis: Editora UEG, 2016. p. 201-224.

KIM, J. H.; KIM, M.; KIM, J. Social activities and health of korean elderly women by age groups. Educational Gerontology, v. 39, n. 9, p. 640-54, 2013.

KIM, J.; YAMADA, N.; HEO, J.; HAN, A. Health benefits of serious involvement in leisure activities among older Korean adults. International Journal of Qualitative Studies on Health \& Well-Being, v. 9 , n. 1, p. 1-9, 2014.

KRIPPENDORFF, K. Content analysis: an introduction to its methodology. London: Sage Publications, 2014.

LEVY, B. R.; SLADE, M. D.; KUNKEL, S. R.; KASL, S. V. Longevity increased by positive selfperceptions of aging. Journal of Personality and Social Psychology, v. 82, n. 2, p. 261-270, 2002.

MARTINS, E. C. Suprir distâncias com o enfoque intergeracional: dos benefícios à intervenção em animação sociocultural. Revista Práticas de Animação, n. 12, p. 48-71, 2019.

MENEGALDO, F. R. Ginástica para todos: por uma noção de coletividade. 2018. 160 p. Dissertação (Mestrado em Educação Física) - Faculdade de Educação Física, Universidade Estadual de Campinas, Campinas, 2018.

MENEGALDO, F. R.; BORTOLETO, M. A. C. Ginástica para Todos: o que a Praxiologia Motriz tem a dizer sobre isso? Conexões, v. 18, ed. esp., 2020a.

MENEGALDO, F. R.; BORTOLETO, M. A. C. Ginástica para todos e coletividade: nos meandros da literatura científica. Motrivivência, v. 32, n. 61, p. 1-17, jan./mar., 2020 b.

MENEGALDO, R. M.; BORTOLETO, M. A. C. The role of time and experience to the gymnastics for all practice: building a sense of collectivity. Science of Gymnastics Journal, v. 12, n. 1, p. 19-26, 2020 c.

MINAYO, M. C. (org.). Pesquisa social: teoria, método e criatividade. 29. ed. Petrópolis: Vozes, 2010.

MORENO, N. L., TSUKAMOTO, M. H. C. Influências da prática da ginástica para todos para a saúde na velhice. Conexões, v. 16, n. 4, p. 468-487, 2018.

MOTA, P. C.; NEVES, R. Práticas intergeracionais e TIC: um contributo para uma revisão da literatura. Instrumento: Revista de Estudo e Pesquisa em Educação, v. 21, n. 1, p. 5-20, 2019.

OLIVEIRA, N. R. C. de O. Ginástica para todos: perspectivas no contexto do lazer. Revista Mackenzie de Educação Física e Esporte, v. 6, n. 1, p. 27-35, 2007.

PAOLIELlO, E.; TOLEDO, E.; AYOUB, E.; BORTOLETO, M. A. C.; GRANER, L. Grupo Ginástico Unicamp: 25 anos. Campinas: Unicamp, 2014.

PARLEBAS, P. Léxico de praxiologia motriz: juegos, deporte y sociedad. Barcelona: Editorial Paidotribo, 2001.

PATRÍCIO, T. L.; BORTOLETO, M. A. C. Festivais ginásticos: princípios formativos na visão de especialistas. Conexões, v. 13, n. esp., p. 98-114, 2015.

PATRÍCIO, T. L.; BORTOLETO, M. A. C.; CARBINATTO, M. V. Festivais de ginástica no mundo e no Brasil: reflexões gerais. Revista Brasileira de Educação Física e Esporte, v. 30, n. 1, p. 199-216, jan./mar. 2016.

PINTO, J. M.; NERI, A. L. Trajectories of social participation in old age: a systematic literature review. Revista Brasileira de Geriatria e Gerontologia, v. 20, n. 2, p. 259-272, 2017. 
RIEDO, C. R. F.; GARCIA, M. F.; SILVA, D. da. O programa UniversIDADE da Unicamp e a modalidade MOOC. Revista de Estudos Aplicados em Educação, v. 2, n. 3. jan./jun. 2017.

SENNETT, R. Juntos: os rituais, os prazeres e a política da cooperação. Rio de Janeiro: Record, 2012.

SILVA, F. S. Contribuições da ginástica para todos para o desenvolvimento das relações sociais em idosos. 2020. 79 p. Dissertação (Mestrado em Educação Física) - Faculdade de Educação Física, Universidade Estadual de Campinas, Campinas, 2020.

SIMÕES, R.; CARBINATTO, M. V. Ginástica para todos: inclusive para o idoso! In: MIRANDA, R. C. F.; EHRENBERG, M. C.; BRATIFISCHE, S. A. (org.). Temas emergentes em ginástica para todos. Várzea Paulista: Fontoura, 2016. p. 167-183

SOARES, D. B.; ALMEIDA, T. L.; BORTOLETO, M. A. C. Autonomia, criatividade e o processo de construção coletiva na ginástica para todos. In: MIRANDA, R. de C. F.; EHRENBERG, M. C.; BRATIFISCHE, S. A. (org.). Temas emergentes da ginástica para todos. Várzea Paulista: Fontoura, 2016. p. 123-152.

TRIVIÑOS, A. Introdução à pesquisa em ciências sociais: a pesquisa qualitativa em educação. São Paulo: Atlas, 1987.

Recebido em: 17 out. 2020.

Aprovado em: 28 nov. 2020. 